\title{
Cuidadores de idosos institucionalizados: vivências de prazer e sofrimento
}

\author{
Caregivers for institutionalized elderly: \\ experiences of pleasure and suffering \\ Cuidadores del adulto mayor institucionalizado: \\ vivencias de placer y de sufrimiento
}

\author{
Pamela Fabíola de Andrade* \\ Carmem Regina Giongo*
}

\section{Resumo}

Esta pesquisa tem como objetivo analisar as vivências de trabalho de cuidadores que atuam em lares geriátricos. Foram entrevistadas cinco cuidadoras, com idade entre 26 e 54 anos. A coleta de dados foi realizada por meio de entrevistas semiestruturadas, com perguntas abertas, possibilitando ao entrevistado falar livremente sobre as questões indicadas. Concluiu-se que estes profissionais têm uma ampla jornada de trabalho, fazendo muito além do trabalho prescrito e doando-se inteiramente para atender às necessidades apresentadas pelos idosos. Além disso, as cuidadoras entrevistadas pareceram não refletir sobre a prática do trabalho e afirmaram não ter escolhido esta profissão, mas vivenciado circunstâncias que as levaram a exercer tal atividade. Foi observado que neste campo de atuação não existem capacitações ou aprimoramento para o desempenho da função, implicando em riscos para a saúde física e mental destes profissionais.

Palavras-chave: saúde mental; psicologia da saúde; cuidadores; institucionalização; trabalho.

* Psicóloga Universidade Feevale. E-mail: pamelal@feevale.br

** Docente no curso de Psicologia Universidade Feevale, Pós Doutoranda em Psicologia Social e Institucional. E-mail: ca.aiesec@gmail.com 


\section{Abstract}

This research aims to analyze the processes of health and illness in caregivers who work in geriatric homes.Five caregivers, aged between 26 and 54 years old, were interviewed. Data was collected through semi-structured interviews with open-ended questions, allowing the interviewees to speak freely aboutthe issues at hand. It was established that these professionals have an extensive working day, doing much more than the work assigned to them and that they dedicate themselves entirely to serve the elderly. Moreover, the caregivers who were interviewed did not seem to reflect about the work and stated they had not chosen this profession, but had faced circumstances that led them to perform this activity. It was observed that in this field of activity there is no training to improve their performance, resulting in risks to the professionals' physical and mental health.

Keywords: mental health; health psychology; caregivers; institutionalization; work.

\section{Resumen}

El objetivo de esta investigación es analizar las vivencias de trabajo de los cuidadores que actúan en las residencias geriátricas. Para ello, han sido entrevistadas cinco cuidadoras, con edades entre 26 y 54 años. Los datos han sido recolectados a través de entrevistas semiestructuradas, con preguntas abiertas, permitiendo a los entrevistados hablar libremente sobre las cuestiones planteadas. Se ha concluido que estos profesionales poseen una extensa jornada laboral, desarrollando muchas actividades que van más allá del trabajo prescrito y entregándosetotalmente para atender a las necesidades de los adultos mayores. Además, parece que los cuidadores entrevistados no reflexionan sobre su práctica laboral y han afirmado, incluso, no haber elegido dicha profesión, solamente han ido vivenciando las circunstancias que las llevaron a ejercer esta actividad. Se ha observado que en este campo de actuación no hay capacitaciones para el desempeño de dicha función, lo que resulta en riesgos para la salud física y mental de estos profesionales.

Palabras clave: salud mental; psicología de la salud; cuidadores; institucionalización; trabajo.

\section{INTRODUÇÃO}

A saúde e o bem-estar são dois critérios fundamentais na vida do ser humano. Isso se aplica também ao ambiente de trabalho, sendo ele, um dos principais elementos no processo de saúde e adoecimento dos sujeitos. Para Dejours (1992), os trabalhadores procuram alcançar o bem-estar mediante a 
conquista de algumas das dimensões físicas, mental e/ou social de maneira criativa. Este processo promove a saúde quando há espaço de adaptação do trabalho ao homem e também do homem ao seu trabalho. Neste sentido, saúde mental no trabalho não significa ausência de sofrimento, mas a construção de espaços coletivos nos quais os trabalhadores possam transformar os fatores da organização do trabalho que geram sofrimento.

Dentre os diversos campos de atuação profissional, estão os trabalhadores da área da saúde. Desde a década de 1940, a Organização Mundial da Saúde (OMS) considera difícil a condição de trabalho dos profissionais da saúde de vários países (Zanon \& Marziale, 2000). São inúmeros os fatores que afetam a saúde destes profissionais, dentre eles podem ser citados os riscos ocupacionais, a sobrecarga de trabalho, a vivência diária com a morte, as pressões provenientes da organização do trabalho, o medo do erro, as longas jornadas de trabalho, entre outros. Além disso, o sofrimento psíquico é um fator manifestado com frequência nos profissionais que atuam no âmbito da saúde (Brotto \& Dalbello-Araujo, 2012).

No âmbito da saúde, uma categoria profissional ainda pouco discutida é a de cuidadores de idosos. A revisão da literatura realizada para produção deste estudo apontou para uma carência de investigações no Brasil acerca da saúde mental de cuidadores de idosos institucionalizados, denominados cuidadores formais. Estes profissionais ainda não têm um papel reconhecido nacionalmente, não há pré-requisitos que regulamentem de forma precisa a formação de cuidador, sendo necessário, assim, que as instituições de longa permanência para idosos contratem cuidadores que podem ou não possuir a qualificação adequada para atender suas demandas (Sampaio, Rodrigues, Pereira, Rodrigues, \& Dias, 2011). É emergente, portanto, o direcionamento de atenção e de suporte ao profissional que atua como cuidador de idosos, com o intuito de promover a este sujeito qualidade de vida e saúde.

Esta profissão foi recentemente conhecida em nosso país e sua função está consolidada pelo Ministério do Trabalho e Emprego, através de reconhecimento e inserção da Classificação Brasileira de Ocupações, sob o código 5.162-10 (cuidador de idosos dependentes ou não e cuidador de idosos institucionalizados). Existem poucas iniciativas no campo da educação formal que contribuem para a consolidação desta atividade 
profissional, apesar do elevado aumento dessa categoria profissional. Outrossim, ainda não há critérios definidos ou pré-requisitos estabelecidos para regulamentar a formação destes profissionais (Ribeiro, Ferreira, Ferreira, Magalhães \& Moreira, 2008).

Apesar do expressivo crescimento e importância desta profissão, nem sempre há uma formação adequada para estes profissionais, sendo que a capacitação dos cuidadores se torna um item de fundamental valor para o desempenho das funções que englobam a profissão. Born (2008) ressalta que os cursos que são realizados no Brasil atualmente não seguem um padrão, ficando o programa a critério do preparo do profissional e da experiência daqueles que o organizam. O despreparo do cuidador pode trazer sérios danos ao paciente resultando, até mesmo, em hospitalizações. Também pode gerar ansiedade e maior desgaste físico, ocasionando situações de risco para ambos: o cuidador e quem recebe o cuidado (Perlini, 2001).

Segundo Alvarez (2001), este trabalho exige muita energia, pois cuidar de uma pessoa adulta engloba tarefas pesadas; é necessário ter condicionamento físico capaz de atender às demandas do sujeito, como, por exemplo, a de locomoção e de banho (Rocha, Vieira, \& Sena, 2008). Diante da perspectiva de aumento da demanda de trabalho para os profissionais que atuam como cuidadores de idosos e da precarização no que se refere ao cuidado, amparo e formação destes trabalhadores, tornam-se relevantes e necessários estudos que possam dar visibilidade para este contexto. Logo, entende-se que ações como a promoção da saúde e a capacitação dos cuidadores de idosos podem trazer benefícios diretos tanto para a qualidade de vida dos idosos institucionalizados, quanto para a saúde mental do trabalhador.

Neste contexto, o presente trabalho possui o objetivo geral de analisar as vivências de trabalho de cuidadores que atuam em lares geriátricos. Como objetivo específico, busca-se descrever a organização do trabalho e suas repercussões no processo de saúde e adoecimento destes trabalhadores. Através dos resultados, pretende-se dar visibilidade para esta categoria profissional, ampliando-se a discussão acerca dos processos de saúde e adoecimento dos trabalhadores inseridos neste meio. Além disso, espera-se 
contribuir para a construção de direitos destes profissionais, discutindo-se os aspectos formais de trabalho relacionados à categoria e às possibilidades de atuação e intervenção da Psicologia.

\section{METODOLOGIA}

Este estudo possui um delineamento exploratório-descritivo (Prodanov \& Freitas, 2013). Para sua realização foram entrevistadas cinco cuidadoras de idosos institucionalizados que estavam atuando em lares geriátricos localizados na Região Metropolitana de Porto Alegre/RS. Este número foi delimitado por critério de saturação. A população do estudo foi totalmente composta por mulheres, com idade entre 26 e 54 anos. Quanto à escolaridade, uma possuía o Ensino Médio completo, uma possuía o Ensino Médio incompleto e três possuíam Ensino Fundamental completo. O tempo de atuação na função de cuidadora das participantes variou entre cinco meses e dezesseis anos. A renda média apresentada foi de um a dois salários mínimos para todas as participantes.

Como instrumentos para a coleta de dados foi utilizado um questionário sociodemográfico e uma entrevista semiestruturada. O roteiro de entrevista foi adaptado a partir do modelo apresentado por Mendes (2007), que orienta que as perguntas sejam abertas e permitam a livre expressão dos trabalhadores. A coleta de dados foi realizada no mês de março de 2015 em dois lares geriátricos, no horário de trabalho dos funcionários que aceitaram participar do estudo. Todas as participantes assinaram o Termo de Consentimento Livre e Esclarecido e permitiram a gravação das entrevistas em áudio. Destaca-se que a pesquisa cumpriu com todos os procedimentos éticos previstos pela legislação. O material coletado nas entrevistas foi analisado e interpretado através da técnica de Análise de Conteúdo de Bardin (2011). Para a análise interpretativa, ao longo dos relatos foram criadas categorias, sendo elas: Organização do Trabalho; Vivências de Prazer no Trabalho; Vivências de Sofrimento no Trabalho e Estratégias Defensivas. A identificação das cuidadoras ao longo do texto será feita por nomes fictícios. Este estudo seguiu os critérios da Declaração de Helsinki da Associação Médica Mundial. 


\section{ANÁLISE E DISCUSSÃO DOS RESULTADOS}

\section{Organização do trabalho}

Um dos principais elementos na análise do processo de saúde e adoecimento dos trabalhadores em contextos institucionais é a organização do trabalho (Dejours, 2008). Através das falas dos cuidadores de idosos entrevistados neste estudo a organização do trabalho foi caracterizada pela rotina do trabalho, carga horária, autonomia, função da gestão, escolha profissional e ausência de capacitação. Quanto à rotina de trabalho, todas as participantes relataram a realização de atividades semelhantes. Dentre as principais mencionadas estão: a alimentação dos idosos (em média cinco vezes ao dia entre café da manhã, lanche da manhã, almoço, lanche da tarde e jantar), a higienização dos idosos (corte de unhas e barba, escovação dos dentes, banho, troca de fraldas), o apoio na realização de necessidades básicas (fornecimento de água e auxílio para ida ao banheiro, inúmeras vezes por dia), entre outras.

A demanda não é pequena, fato este que dificultou a realização da entrevista. As entrevistadas não tinham muito tempo para sua realização e se fez perceptível a preocupação com os idosos durante o momento em que estávamos juntas. A todo instante elas observavam o local onde os idosos estavam e também controlavam o horário no relógio. Tinham autorização da gestão dos locais para a realização da entrevista, aceitaram participar, mas não se permitiram focar na atividade. Este aspecto pode ser analisado do ponto de vista da saúde mental das trabalhadoras, visto que a atividade profissional que realizam implica no cuidado com a saúde e com a vida de outra pessoa. Este fazer exige constante vigilância e atenção, podendo levar à tensão e à falta de momentos de descanso no local de trabalho. Assim, o mesmo trabalho que gratifica, quando realizado com afinco, também exige do trabalhador esforço, capacidade de concentração e de raciocínio, implicando no desgaste físico ou mental (Franco, Druck, \& Seligmann-Silva, 2010).

A rotina de trabalho vinculada diretamente com o cuidado do outro faz com que os trabalhadores se envolvam intensamente com as pessoas 
que por eles são cuidadas. Eles fazem o uso constante da mobilização subjetiva, que é definida como um processo que se caracteriza pelo uso da inteligência operária e pelas emoções despertadas pelo fazer do trabalho. $\mathrm{O}$ uso destes recursos pelos trabalhadores depende da dinâmica contribuição-retribuição simbólica, que implica no reconhecimento da competência do trabalhador pelos pares e pela hierarquia. Este processo é vivenciado de forma particular por cada trabalhador, não sendo ele prescrito. Ele é item fundamental no processo de gestão coletiva, evitando o uso de estratégias defensivas (Mendes, 1995).

De acordo com o descriminado anteriormente, estes profissionais têm uma rotina de trabalho cansativa e que se assemelha no decorrer dos dias, tendo eles uma função primordial, que é a de cuidado, proporcionando a todo o momento o bem-estar do idoso institucionalizado. Além disso, a prática deste trabalho, de cuidado, desperta nos profissionais sentimentos e emoções relacionados à sua própria vida, como, por exemplo, o cuidado dos pais, o próprio envelhecimento e também a morte.

Quanto à jornada de trabalho, estes profissionais possuem uma característica de fazer além do trabalho prescrito. Doam-se inteiramente para atender às necessidades dos idosos, seja por meio de carinho e atenção, como pela participação de eventos e demandas que o local promove. Ademais, muitas vezes eles fazem com que os idosos passem a fazer parte da sua própria família.

Estes acontecimentos podem ser analisados de duas maneiras: como um benefício adicional oferecido pela instituição de acolhida ao idoso, que recebe uma assistência que vai além do cuidado físico e que reflete na saúde mental dos idosos; ou como uma prática que pode trazer ao trabalhador sofrimento, pois através disso, acabam excedendo a jornada de trabalho, privando-se de descanso. Muitas vezes os trabalhadores que se encontram em desgaste físico e emocional não conseguem associar este estado às horas excedidas que se dedicaram para atender à demanda que o local exige.

Dentro do horário de trabalho contratual, as entrevistadas relatam cumprir o mesmo horário de trabalho, das 7 h às $19 \mathrm{~h}$. Nos relatos das trabalhadoras aparecem dois aspectos de avaliação da jornada de trabalho. Por um lado, é desgastante, em função da longa jornada diária, mas por 
outro agrada, no que se refere a trabalhar a carga horária 12×36 (dia sim e dia não). Carla diz, por exemplo: "Eu me interessei também por causa do horário, no outro dia eu posso resolver várias coisas, eu posso até estudar".

O que se observa no contexto de atuação dos profissionais da saúde é que este horário de trabalho permite aos profissionais trabalharem em mais de um local, com o objetivo do obter um aumento salarial. A dupla jornada de trabalho para os profissionais da área da saúde é uma prática comum. Isso ocorre em função da situação econômica da área da saúde, com salário insuficiente para o sustento próprio e da família, os levando assim às exaustivas jornadas de trabalho em mais de uma instituição.

Esta prática traz riscos à saúde mental do trabalhador, desfavorecendo a vida social, na medida em que dificulta o convívio com familiares, amigos e também o cuidado de si, o que pode ocasionar adoecimento e sofrimento. Desta forma, o profissional se expõe ao risco da sobrecarga física e psíquica, ou a outros agravos decorrentes de condições do próprio trabalho (Espindola \& Fontana, 2012). Assim, ao se submeter à dupla jornada de trabalho, o profissional da saúde pactua com a ideologia de que o interesse no capital está acima dos interesses da sua saúde, seja ela física ou mental (Sanna, 2007).

Um elemento importante na promoção da saúde mental no trabalho são os espaços nos quais o trabalhador tem a possibilidade de se expressar e de contribuir no âmbito do seu trabalho. Com relação a isso, as entrevistadas mostraram satisfação na resolução de problemas e demandas junto à gestão dos locais entrevistados. No entanto, apesar de as entrevistadas relatarem um bom nível de participação no modelo de gestão da instituição, observa-se que elas parecem refletir pouco sobre o trabalho. Este processo de reflexão possibilita que o sujeito busque soluções ou alternativas que promovam a saúde mental. Diante da pergunta "me fala sobre o que poderia ser melhorado no seu ambiente de trabalho", a maioria das entrevistadas falou que nunca havia pensado sobre isso. Carla, por exemplo, responde dizendo: "Eu não sei porque eu nunca trabalhei em outros lares assim, então eu não tenho muita noção do que que poderia ser melhor... Eu nunca pensei... Não tenho muita noção assim do que que poderia melhorar". 
Esta dificuldade apresentada pelas entrevistadas pode estar relacionada à exaustiva rotina de trabalho e à ausência de espaços coletivos de reflexão, dificultando o pensar sobre as vivências profissionais. Observou-se que elas não possuem espaços coletivos para que esta demanda seja abordada, restringindo-se o debate acerca do sentido do trabalho ou mesmo do significado do sofrimento. Outro aspecto que chamou a atenção na pesquisa é de que as entrevistadas, apesar de relatarem algumas satisfações relacionadas ao trabalho, não possuíam como objetivo de vida atuar nesta profissão. A atividade hoje desenvolvida se iniciou pelo cuidado de um familiar, por indicação de amigos, ou pela procura de um emprego, que acabou resultando no cuidado de idosos. "Eu decidi essa profissão, por causa que uma amiga minha trabalhava aqui, daí ela falou dessa vaga que tinha e eu tava procurando emprego e já fazia um tempo que eu tava procurando, e daí eu resolvi vim ver a vaga e acabei ficando, acabei”, explica Carla.

Além de não refletirem sobre a escolha da profissão, é comum, neste local de trabalho, a troca de funções como, por exemplo, as cozinheiras ou profissionais que atuam na lavanderia ou higienização passarem a exercer a função de cuidadora. Esta seria uma "promoção", pois normalmente há um aumento salarial que dispensa o conhecimento específico para realizar as atividades que englobam o cargo. Em consequência da falta de escolha prévia da profissão, não há uma preparação anterior para o desempenho das atividades exigidas pelo cargo. A maioria das participantes da pesquisa possui apenas o ensino fundamental completo, sem nenhum tipo de curso ou capacitação que aborda o conteúdo necessário para a qualidade do serviço de cuidador. Trabalho este que exige aspectos como manuseio de pacientes, cuidados específicos para com os idosos, conhecimentos básicos de escoriações, além de todo o aspecto emocional, pois os idosos, por vezes, estão sensíveis e emotivos.

Quando perguntado às entrevistadas que tipo de capacitação seria relevante para a realização da atividade profissional, Gisele destacou o seguinte: "Paciência, visão ampla para verificar se está tudo bem. Conhecer as doenças e limitações. Cuidador não é só saber trocar fralda e dar banho”. Rita também respondeu esta pergunta e disse que "Tinha que ter um curso de cuidador mesmo, pelo menos pra gente aprender o básico”. Assim, faz-se 
necessária a realização de uma capacitação para estes profissionais que, em grande parte, não possuem conhecimento específico para a execução das demandas, sejam elas teóricas ou práticas. Além disso, foi possível perceber que estes profissionais trabalham em longas (ou até mesmo duplas) jornadas de trabalho diárias, fato este que pode refletir diretamente na sua saúde mental. É fundamental, portanto, que a organização do trabalho ofereça um espaço de autonomia e posicionamento, podendo trazer questões da rotina do trabalho, além de melhorias ou sugestões que aperfeiçoe o seu trabalho, refletindo na instituição como um todo.

Também é imprescindível a criação de capacitações e/ou treinamentos para que os cuidadores exerçam suas atividades de trabalho com mais qualidade e segurança, obtendo-se, desta forma, a redução da ansiedade e do sofrimento no exercício da profissão. Para que a assistência prestada ao idoso seja de qualidade, o cuidador precisa desenvolver habilidades e competências específicas e isso é diretamente trabalhado em capacitações e cursos de aperfeiçoamento (Sampaio et al., 2011). Ademais, é neste âmbito que o cuidador irá perceber o quão importante é a prestação de um serviço humanizado, ético e que propicie ao sujeito por ele cuidado um envelhecimento saudável e, acima de tudo, com qualidade de vida.

\section{Vivências de prazer no trabalho}

O prazer no trabalho é um dos principais fatores de saúde mental (Dejours, Abdoucheli, \& Jayet, 1994). Através dos relatos das cuidadoras de idosos entrevistadas neste estudo, observou-se que o prazer aparece associado à satisfação com as rotinas de trabalho, ao horário de trabalho, ao aprendizado cotidiano, ao relacionamento com os idosos, à atuação profissional ou, ainda, ao convívio com os colegas. As falas das entrevistadas, ao relatarem suas experiências e convivência com os idosos, eram carregadas de sentido e de emoção. Elas relatam levar como experiência os acontecimentos vividos no âmbito do trabalho. Gisele disse, por exemplo: "É o que eu gosto, ficar cheirando a talco, cheirar perfume barato, igual o que eu tô 
sentindo agora, cristalzinho [risadas], daí tu fica assim, entendeu? Cheirar perfume barato, cheirar xixi, que muitas vezes me aconteceu, de eu ir pra escola, chegar e sentar na sala e sentir o cheiro de mijo em mim".

Assim, demonstra satisfação na atuação da profissão, levando consigo experiências e aprendizados que são significativos, para além do âmbito do trabalho. Além disso, as entrevistadas ressaltaram a importância do trabalho coletivo neste contexto. Este processo pode ser observado em algumas falas como quando Carla cita que "aqui tem muito coleguismo".

Outro elemento que se destacou nas falas das entrevistadas foi o reconhecimento. O reconhecimento é uma vivência de prazer, principalmente quando vinculado à realização de uma tarefa de valor importante para o indivíduo, além de ser importante para a sua instituição de trabalho e para a sociedade (Prata, 2013). Dejours (1999) afirma que "do reconhecimento depende, na verdade, o sentido do sofrimento". A falta de reconhecimento pode ser um item influenciador para o sofrimento, porque, no caso dessa ausência, há uma tendência de o cuidador desmobilizar-se. Quanto as cuidadoras entrevistadas esta vivência aparece principalmente através do sentimento de satisfação, tanto do carinho recebido pelos idosos como da satisfação com relação ao trabalho. Rita fala do "[...] amor que eles [idosos] sentem por ti [...] Estão sempre te agradecendo". Gisele também sente o reconhecimento e diz que "é um trabalho satisfatório".

A valorização do esforço permite que o sujeito encontre realização em si mesmo através de seu trabalho (Mendes, 2007). Desta forma, esse reconhecimento influencia positivamente a saúde mental do trabalhador, fornecendo a ele momentos de prazer. E para este prazer ser intenso, diante deste cenário, o reconhecimento não deveria ser relatado unicamente relacionado aos idosos, mas também apontado pela instituição e também pela sociedade como um todo, reconhecendo e agregando o trabalho deste profissional. Apesar de as entrevistadas se sentirem reconhecidas pelos idosos, não houveram relatos de reconhecimento via organização do trabalho.

A inteligência prática ocorre quando a instituição permite que o trabalhador desenvolva novas formas para o desempenho de suas atividades, transgredindo o trabalho prescrito, buscando novas alternativas, mais eficazes, de realizar a tarefa (Carrasqueira \& Barbarini, 2010). Nos 
relatos das entrevistadas, a inteligência prática se manifesta através de um "jogo de cintura", para fazer com que os fatos ou mudanças realmente ocorram. Na fala da entrevistada Gisele, fica clara a utilização da sua inteligência prática para fazer com que a demanda seja atendida, proporcionando o bem-estar do idoso. Ela cita: "Eu vejo que eles tão comendo diferente, como tem paciente aqui que eu sei que não pode comer, mas a família trazem, eu chego e falo, goste ou não goste, eu falo: ela tá ficando um pouco obesa devido às coisas que ela tá comendo”. Assim, a inteligência prática pode ser um item influenciador para a saúde mental do sujeito, pois faz o uso de alternativas para melhorar o seu processo de trabalho, dentro da sua capacidade, mas vai além do trabalho prescrito. Isso vai trazer benefícios tanto para a instituição como para o trabalhador que teve a autonomia e a possibilidade de aplicar novas formas de trabalho, acarretando na melhor qualidade do processo.

\section{Vivências de sofrimento no trabalho}

Quando o trabalho não causa no sujeito sentimentos de satisfação, alegria e prazer, ele pode ser visto com um olhar negativo, estando associado ao sofrimento (Prata, 2013). O sofrimento surge no âmbito do trabalho a partir do momento em que há um bloqueio na relação do trabalhador com a sua organização de trabalho, em virtude de dificuldades de negociação das diferentes forças que envolvem o desejo do trabalhador e o desejo da produção (Mendes, 2007). Dentre estes aspectos, um elemento bastante presente foi a sobrecarga física. Este tipo de sofrimento foi apontado pelas pessoas entrevistadas como um item grande causador de sofrimento. Gisele explica, por exemplo: "Tenho muita dor física, sim, eu tenho muito problema de coluna. Os braços da gente, tem horas que tu não aguenta, tudo dói, tudo, dói muito, o pescoço principalmente”. Nicole também fala sobre esta sobrecarga: “Ah, 100\% né, porque dói aqui, dói ali, né, mas isso passa também, né... Não é assim. Eu, na coluna, assim, não tenho problema. Às vezes dói, mas é normal, né, do dia a dia, né".

Através destes relatos percebe-se que as entrevistadas vivenciam uma intensa sobrecarga física e que há um grande desgaste com o manuseio de 
pacientes, sendo esta prática realizada várias vezes ao dia (nas horas do banho, da ida ao banheiro, de colocar e tirar o idoso da cama). A entrevistada Nicole relata que possui dores em vários locais do corpo e, logo em seguida, utiliza mecanismos e transforma estas dores em algo normal, fazendo com que este sentimento não a atrapalhe, nem mesmo faça parte do adoecimento do corpo por causa do trabalho. Corroboram estes dados uma pesquisa realizada com dezessete profissionais da área da enfermagem da cidade de São Paulo, que mostrou que 92,9\% dos entrevistados sofrem com a sobrecarga física pelo manuseio de pacientes, fato que causa sérios danos à saúde destes trabalhadores (Zanon \& Marziale, 2000). Diante disso, há a patologia da sobrecarga que é caracterizada pelo processo no qual o trabalhador assume uma carga de trabalho que está além de suas capacidades, com o intuito de atingir melhores resultados e de atender às demandas da organização do trabalho de alavancar metas de produtividade cada vez maiores (Dejours, 2007).

O convívio constante com a dor e com a morte gera, nos profissionais da área da saúde, sofrimento. Este, muitas vezes não é relatado ou compartilhado, prevalecendo a lei do silêncio (Kovács, 2005). A morte de pacientes foi um assunto que demonstrou profundo sofrimento por parte dos entrevistados e também apareceu naturalizado em algumas falas. Segundo Carla: “Tranquilo, é comum, é mais um pra gente né”.

Desta forma, pode-se perceber que todas as entrevistadas trataram a morte como algo normal, como um acontecimento rotineiro da nossa vida, o que não deixa de ser um fato real. Porém, elas fazem o uso de estratégias defensivas para lidar com esta perda. Por vezes, não elaboram o luto, fazendo parecer que "foi mais um que morreu". De um lado, seria fundamental a elaboração do luto, o sentimento da perda, por outro, elas acabam naturalizando a morte como uma forma de continuar trabalhando.

Este acontecimento pode levar o trabalhador ao adoecimento mental, no momento em que ele cria um sentimento de culpa e de fracasso frente ao caso. Esse sentimento pode ser uma fonte de estresse e de sofrimento psíquico para esses trabalhadores, interpretando o ocorrido como fracasso pessoal e falha no trabalho desenvolvido (Mota, Gomes, Coelho, Lunardi, \& Sousa, 2011). Os profissionais da área da saúde, especificamente os que 
trabalham em hospitais, são os que mantêm maior contato direto e prolongado com os pacientes, sendo os primeiros que atendem às suas necessidades e, portanto, eles estabelecem vínculos afetivos. Este fato pode ser benéfico para o cuidado, no entanto pode tornar o trabalhador vulnerável ao estresse laboral (Santos \& Hormanez, 2013). Isso não é completamente distinto do que ocorre com os profissionais que atuam em lares geriátricos, que possuem características semelhantes ao ambiente hospitalar, com cuidado 24 horas.

A entrevistada Nicole não teve condições de concluir a entrevista quando abordado o assunto morte, pois ficou emocionada. Acontecimento este que comprova o quanto os profissionais interiorizam um sentimento de perda e tristeza. Contudo, simultaneamente, demonstram que se trata de um acontecimento normal, conforme descrito na fala de Nicole: "Ah, a gente fica nervosa daí, né? Normal... Como uma pessoa quando perde alguém”. Assim, percebe-se que o trabalhador pode estar em profundo estágio de sofrimento com uma grande sobrecarga física, principalmente em função de pacientes que dependem integralmente de sua ajuda para se locomover. Além disso, há casos de morte de pacientes, sofrida, mas não revelada, que afeta mas que ao mesmo tempo é transformada em algo natural da vida, para que ela não seja profundamente sentida, indeterminadamente doída.

\section{Estratégias defensivas}

As estratégias defensivas são mecanismos que o sujeito usa para mudar, transformar e diminuir o sofrimento no trabalho, resultantes da composição entre o sofrimento e a luta individual e/ou coletiva contra este sentimento negativo (Lopes, 2010). As principais estratégias identificadas nas falas das trabalhadoras foram a banalização da morte dos idosos e o não pensar sobre o trabalho e a escolha profissional temporária, com o intuito de inviabilizar o sofrimento, presente em todas as entrevistadas.

Conforme descrito anteriormente, a morte é um item de grande sofrimento, mas as entrevistadas utilizam estratégias de defesa para suportar este acontecimento que, na profissão de cuidador, é extremamente rotineiro. Para Rita: “[...] ela acabou falecendo, daí, foi normal, totalmente. Hoje em 
dia é normal, acabou falecendo dois vôs agora, semana passada. Acabou falecendo e normal, assim, pra mim... Não tenho dificuldade, assim”. Gisele também explica que é "tranquilo... Não me afeta em nada, nada, nada. [...] Mas é natural, vai acontecer com ele e todo mundo. Só dá aquele 'back', ai, morreu, que pena [...]".

Outra estratégia apresentada pelas entrevistadas foi referente à escolha profissional. Durante a entrevista, muitas cuidadoras mencionaram que a atuação nesta profissão é momentânea, não havendo o desejo delas de permanecer na atividade futuramente. Além disso, abordam o vínculo positivo com o idoso como um dos motivos para permanecem na instituição. Uma estratégia defensiva que chamou a atenção durante a pesquisa foi referente ao relato de uma das entrevistadas, Gisele, que diz: "Eu chego 7 horas da manhã, mas começo a trabalhar 7h2omin. Eu não trabalho antes de tomar um café preto e fumar um cigarro, daí... Aí eu começo, né”. A cuidadora utiliza este meio como forma preparatória para iniciar o trabalho. O fumo, na maioria dos casos, significa uma forma de defesa para quebrar a tensão vivida no âmbito do trabalho, além disso, tem um caráter defensivo também contra a ansiedade (Martins, Robazzi, \& Bobroff, 2010). Além disso, Gisele também relata ter se apropriado de uma cama, para descanso diário: "Eu pego um quarto que tem ali, que não tem mais ninguém, que morreu um vô já faz algum tempo, né... Eu arrumei a cama pra mim, a cama dele. Fiz a higienização, peguei pra mim. Aquela lá, não deixo ninguém pegar. Daí eu durmo uma meia hora”.

Observa-se, nesta fala, uma forte mistura de ambientes, pois ela tem a própria cama dentro do ambiente de trabalho, como se fosse a sua própria casa, não havendo a diferenciação do que é seu e o que corresponde ao seu trabalho. Dentro deste modelo de instituição, um espaço para que o trabalhador pudesse descansar durante a sua jornada de trabalho seria considerado um fator de prazer. A partir destas análises entende-se que as estratégias defensivas utilizadas pelas participantes atuam na intensificação das atividades e na alienação das sensações do corpo, agravando ainda mais os sintomas e propiciando o estabelecimento das lesões por esforço repetitivo/distúrbios osteomusculares relacionados ao trabalho (LER/DORTs), entre outras patologias associadas à sobrecarga. Estas estratégias podem 
se apresentar aos trabalhadores como um fator de risco para a saúde, pois diminuem a preocupação com os sintomas físicos vivenciados e, consequentemente, as atitudes de autocuidado.

\section{CONSIDERAÇÕES FINAIS}

Os resultados deste estudo indicam que estes trabalhadores têm uma rotina árdua de trabalho e possuem como característica o fazer além do trabalho prescrito, o que pode levar ao sofrimento. Através da mobilização subjetiva, tornaram-se claras as situações em que se doam para atender a todas as necessidades e demandas dos idosos. Observou-se também que não existem espaços de reflexão sobre os processos relacionados ao trabalho, elemento que acompanha estes trabalhadores desde a inserção neste contexto de atuação até a prática de trabalho atual. Além disso, é precária ou completamente nula a capacitação para o desempenho das atividades antes do início da prática laboral, fazendo com que o indivíduo não possua nenhuma qualificação para o desempenho das atividades que demandam a profissão. Este aspecto agrava os riscos relacionados ao trabalho, além de intensificar as vivências de sofrimento.

Há também poucos aspectos relacionados ao reconhecimento deste profissional, tanto por parte da instituição como da sociedade. Há uma falta de valorização deste trabalho que se faz tão importante no cenário atual, considerando-se que o país tende a precisar cada vez mais destes profissionais. Estes que possuem a função de auxiliar os idosos nos aspectos em que eles não possuam mais condições, sejam elas físicas ou psicológicas, de serem executadas sem auxílio. Além disso, os cuidadores vivem diante da dor e da morte, sendo que estes dois aspectos fazem parte da rotina de trabalho de quem optou por esta profissão, deixando-os, desta forma, propícios ao sofrimento. 


\section{REFERÊNCIAS}

Alvarez, A. M. (2001). Tendo de cuidar: a vivência do idoso e a família cuidadora no processo de cuidar e ser cuidado em contexto domiciliar (Tese de doutorado). Universidade Federal de Santa Catarina, Florianópolis, SC, Brasil.

Bardin, L. (2011). Análise de conteúdo. São Paulo: Edições 70.

Born, T. (Org.). (2008). Cuidar melhor e evitar a violência: manual do cuidador da pessoa idosa. Brasília: Secretaria Especial dos Direitos Humanos.

Brotto, T. C. A., \& Dalbello-Araujo, M. (2012). É inerente ao trabalho em saúde o adoecimento de seu trabalhador?. Revista Brasileira de Saúde Ocupacional, 37(126), 290-305. http://dx.doi.org/10.1590/ So303-76572012000200011

Carrasqueira, F. A., \& Barbarini, N. (2010). Psicodinâmica do trabalho: uma reflexão acerca do sofrimento mental nas organizações. Jornada de Saúde Mental e Psicanálise da PUC-PR, 5(1),1-19.

Dejours, C. (1992). A loucura do trabalho: estudo de psicopatologia do trabalho (5a ed.). São Paulo, SP: Cortez, Oboré.

Dejours, C. (1999). A banalização da injustiça social. Rio de Janeiro, RJ: FGV.

Dejours, C. (2007). Psicodinâmica do trabalho na pós-modernidade. In A. M. Mendes, S. C. C. Lima, \& E. P. Facas (Orgs.), Diálogos em psicodinâmica do trabalho (pp. 33-52). Brasília, DF: Paralelo 15.

Dejours, C. (2008). Addendum: da psicopatologia à psicodinâmica do trabalho. In S. Lancman, \& I. L. Sznelwar (Orgs.), Christophe Dejours: da psicopatologia à psicodinâmica do trabalho (pp. 23-45). Brasília, DF: Paralelo.

Dejours, C., Abdoucheli, E., \& Jayet, C. (Orgs.). (1994). Psicodinâmica do trabalho: contribuições da escola dejouriana à análise da relação prazer, sofrimento e trabalho. São Paulo, SP: Atlas. 
Espindola, M. C. G., \& Fontana, R. T. (2012). Riscos ocupacionais e mecanismos de autocuidado do trabalhador de um centro de material e esterilização. Revista Gaúcha de Enfermagem, 33(1), 116-123. http://dx.doi.org/10.1590/S1983-14472012000100016

Franco, T., Druck, G., \& Seligmann-Silva, E. (2010). As novas relações de trabalho, o desgaste mental do trabalhador e os transtornos mentais no trabalho precarizado. Revista Brasileira de Saúde Ocupacional, 35(122), 229-248. http://dx.doi.org/10.159o/ So303-76572010000200006

Kovács, M. J. (2005). Educação para a morte. Psicologia: Ciência e Profissão, 25(3), 484-497. http://dx.doi.org/10.159o/ S1414-98932005000300012

Lopes, D. M. (2010). Prazer, sofrimento e estratégias defensivas dos agentes comunitários de saúde no trabalho (Dissertação de mestrado). Universidade Federal de Santa Maria, Santa Maria, RS, Brasil.

Martins, J. T., Robazzi, M. L. C. C., \& Bobroff, M. C. C. (2010). Prazer e sofrimento no trabalho da equipe de enfermagem: reflexão à luz da psicodinâmica Dejouriana. Revista da Escola de Enfermagem da USP, 44(4), 1107-1111. http://dx.doi.org/10.1590/ Soo80-62342010000400036

Mendes, A. M. (1995). Aspectos psicodinâmicos da relação homem-trabalho: as contribuições de C. Dejours. Psicologia: Ciência e Profissão, 15(13), 34-38. http://dx.doi.org/10.1590/S1414-98931995000100009

Mendes, A. M. (2007). Novas formas de organização do trabalho, ação dos trabalhadores e patologias sociais. In A. M. Mendes (Org.), Psicodinâmica do Trabalho: teoria, método e pesquisas (pp. 56-69). São Paulo, SP: Casa do Psicólogo.

Mota, M. S., Gomes, G. C., Coelho, M. F., Lunardi, W. D., Fº., \& Sousa, L. D. (2011). Reações e sentimentos de profissionais da enfermagem frente à morte dos pacientes sob seus cuidados. Revista Gaúcha de Enfermagem, 32(1), 129-135. http://dx.doi.org/10.1590/ S1983-14472011000100017 
Perlini, N. M. (2001). Cuidar de pessoa incapacitada por acidente vascular cerebral no domicílio: o fazer do cuidador familiar. Ijuí, RS: Unijuí.

Prata, M. M. (2013). Prazer ou sofrimento no trabalho? A percepção dos empregados públicos reintegrados no CEFET-MG (Dissertação de mestrado). Faculdade Novos Horizontes, Belo Horizonte, MG, Brasil.

Prodanov, C. C., \& Freitas, E. C. (2013). Metodologia do trabalho científico: métodos e técnicas da pesquisa e do trabalho acadêmico (2a ed.). Novo Hamburgo, RS: Feevale.

Ribeiro, M. T. F., Ferreira, R. C., Ferreira, E. F., Magalhães, C. S., \& Moreira, A. N. (2008). Perfil dos cuidadores de idosos nas instituições de longa permanência de Belo Horizonte, MG. Ciência \& Saúde Coletiva, 13(4), 1285-1292. http://dx.doi.org/10.1590/S1413-81232008000400025

Rocha, M. P. F., Vieira, M. A., \& Sena, R. R. (2008). Desvelando o cotidiano dos cuidadores informais de idosos. Revista Brasileira de Enfermagem, 61(6), 801-808. http://dx.doi.org/10.1590/ So034-71672008000600002

Sampaio, A. M. O., Rodrigues, F. N., Pereira, V. G., Rodrigues, S. M., \& Dias, C. A. (2011). Cuidadores de idosos: percepção sobre o envelhecimento e sua influência sobre o ato de cuidar. Estudos e Pesquisas em Psicologia, 11(2), 590-613.

Sanna, M. C. (2007). Os processos de trabalho em Enfermagem. Revista Brasileira de Enfermagem, 6o(2), 221-224.

Santos, M. A., \& Hormanez, M. (2013). Atitude frente à morte em profissionais e estudantes de enfermagem: revisão da produção científica da última década. Ciência \& Saúde Coletiva, 18(9), 27572768. http://dx.doi.org/10.1590/S1413-81232013000900031

Zanon, E., \& Marziale, M. H. M. (2000). Avaliação da postura corporal dos trabalhadores de enfermagem na movimentação de pacientes acamados. Revista da Escola de Enfermagem da USP, 34(1), 26-36. http://dx.doi.org/10.1590/Soo8o-62342000000100004 